\title{
DETERMINATION OF TECHNOLOGICAL PARAMETERS AND INDICATORS OF THE QUALITY OF NEW HERBAL COLLECTION
}

\author{
Anna Kriukova \\ Department of pharmacognosy \\ National University of Pharmacy \\ 53 Pushkinska str., Kharkiv, 61002, Ukraine \\ State Scientific-Research Laboratory of Nuph For Medicinal Substances Quality Control \\ 4 Valentinovska str., Kharkiv, Ukraine, 61168 \\ Inna Vladymyrova \\ Scientific Methodological (Scientific Research) Laboratory on Pharmaceutical Education \\ Department of pharmacognosy \\ National University of Pharmacy \\ 53 Pushkinska str., Kharkiv, 61002, Ukraine
}

\begin{abstract}
Rheumatic diseases include more than 1000 nosological forms, among which the highest incidence is osteoarthritis, rheumatoid arthritis and osteoporosis. The predominantly advanced age, the presence of comorbid diseases, the duration of the course of the disease and the need for concomitant treatment complicate the conduct of anti-inflammatory and analgesic therapy in such patients. Herbal medicines, in particular in the form of doses, due to the mildness of the action and the absence of significant side effects, can be used in the complex therapy of the acute period of rheumatic diseases, as well as for the prevention of relapse.

The aim of the presented work was to develop the composition, technology and determination of the quality indices of herbal collection, which reveals analgesic and anti-inflammatory properties and can be used for the prophylaxis and auxiliary therapy of a number of conditions in rheumatology.

Materials and methods. In the course of research, the methods used in the State Pharmacopoeia of Ukraine 2.0 (SPHU) were used.

Results. As a result of the analysis of literary data and our own experimental studies on the chemical composition and pharmacological activity of certain types of medicinal plant material, we have developed herbal collection that is recommended for the treatment and prevention of rheumatic diseases of the joints. Studies have been conducted on the development of quality collection indicators, which guarantee the effectiveness, safety, reproducibility of the imposed collection. The basic technological parameters of the raw material are determined: specific, bulk and volume mass, porosity, degree, degree of shredding. In order to prevent uneven mixing, an optimal degree of grinding of the raw material of the investigated collection, which ranges from $0.20 \mathrm{~mm}$ to $0.35 \mathrm{~mm}$, is established, which allows obtaining a homogeneous mixture and contributes to the maximum yield of extractive and active substances. A series of experimental works aimed at studying the influence of the method of infusion (for 15, 30, 45, 60 minutes and until complete cooling) on the quality of the collected water extracts from the collection was conducted. The optimal method for setting the collection for 60 minutes is the best, since the content of extractives and flavonoids in the aqueous extract was highest and amounted to $49.57 \pm 0.52 \%$ and $0.52 \pm 0.03 \%$ respectively.

Conclusions. The composition of the herbal drug was developed: Harpagophyti radix, Sophorae alabastra, Valvae fructus Phaseoli vulgaris, Polygoni avicularis herba with the following ratio of components 50:20:20:10. The technological parameters of the raw material are studied: specific, volumetric and bulk mass, porosity, singularity of raw materials. The optimum degree of shredding of raw material is established, which helps to maximally remove biologically active substances and extractives. Experimental way is determined the optimal mode of collection, which can be recommended to the consumer to obtain the maximum therapeutic effect.
\end{abstract}

Keywords: rheumatology, herbal collection, Harpagophytum procumbens, standardization.

\section{Introduction}

Herbal medicines occupy a significant place in modern pharmacotherapy. This is due to several advantages over synthetic analogues: softness of phytopreparations, absence of significant 
manifestations of negative side effects, allergic reactions, lack of drug dependence, low toxicity. Many years of experience in the use of herbal medicinal products in clinical practice indicates their effectiveness in the treatment of many, especially chronic diseases, requiring long-term therapy with drugs [1].

Rheumatic diseases of the joints is one of the following groups requiring prolonged anti-inflammatory, analgesic therapy due to joint pains, their deformation and deformation, limitation of movements, changes in the tendon-ligament apparatus of the joints and surrounding muscles [2]. In this regard, herbal medicines may be recommended, in particular in the form of collections [3, 4].

In the production of plant products in different dosage forms, much attention is paid to the study of technological properties of plant material [5, 6]. Efficiency of extraction, in particular the output of BAS in the process of extraction of plant material depends on the technological properties of raw materials and hydrodynamic conditions of the process [7, 8]. Technological indices of raw materials depend on the grinding of medicinal plant raw material (MPRM) particles, which characterizes the surface of extraction [9]. In addition, the degree of grinding of plant material particles must be taken into account at the stage of mixing the components when preparing the collection.

The completeness of the BAS output when preparing water extracts is influenced by other factors, among which the extraction mode is significant [10]. Therefore, when developing a rational technology for receiving infusions, it is necessary to substantiate the method of application for the consumer.

\section{Aim of the research}

The aim of this study was to develop a composition, a technological scheme for the production of herbal remedies and to establish an optimal method of use for consumers.

\section{Materials and methods}

The quality of the MPRM depends on the compliance of its quality indicators with the requirements of the current normative documentation. Therefore, in order to establish the quality of the raw material, as well as the developed fee for the reduced version, quality indicators were determined in accordance with the requirements of the SPHU 2.0: "Loss in mass at drying", "General ash", "Extractive substances" [11].

The specific mass was determined as the ratio of the weight of absolutely dry crushed raw material to the volume of plant tissue. Bulk mass was determined as the ratio of the mass of crushed raw material at a natural moisture to its full volume, which includes pores, cracks and capillaries, filled with air. The bulk density was determined as the ratio of the mass of the crushed raw material at the natural moisture to the total volume consumed by the raw material, which includes pores of particles and voids between them. The porosity of the raw material characterizes the size of the cavities within the raw material particles and is determined as the ratio of the difference between the specific and volumetric masses to the specific mass. Cutting of the layer is defined as the ratio of the difference between the specific and bulk masses to the specific mass $[11,12]$.

To establish the optimal degree of crushing MPRM, two samples of collection with different degree of purity of raw materials were investigated.

The size of the particles of the sampling number 1 was $0.35-5.00 \mathrm{~mm}$ : grass $-0.35-1.5 \mathrm{~mm}$, fruit $-0.35-3.5 \mathrm{~mm}$, rhizomes and roots $-0.35-5.0 \mathrm{~mm}$.

The size of the particles of the sampling number 2 was $0.35-2.0 \mathrm{~mm}$ : grass $-0.35-1.0 \mathrm{~mm}$, fruit $-0.35-1.5 \mathrm{~mm}$, rhizomes and roots $-0.35-2.0 \mathrm{~mm}$.

The feedstock was individually crushed, weighed and mixed in accordance with the developed composition and extracted with purified water R. The content of the extractives and flavonoids was determined according to the methods of SPHU 2.0. [12].

\section{Experimental procedures.}

The choice of the components of the collection is due to their particular biological activity, which in turn provide the proposed collection of the expressed anti-inflammatory and analgesic properties. Due to the presence of BAS sophora buds, the collection reveals P-vitamin action, herbs of doorweed - diuretic action, fistula of beans regulate metabolic processes in the body. 
Harpagophyti radix have anti-inflammatory, analgesic and diuretic effects due to the presence of such BASs as iridoid glycosides (mainly harpagosides, harpagids and procumbids), sugars (tetrasaccharides, stahizoses), triterpenoids (oleanol, ursolic acids), phytosterols ( $\beta$-sitosterol), aromatic acids (coffee, cinnamon, chlorogenic), flavonoids (luteolin, campferol) $[13,14]$.

Sophorae alabastra contains euflavonoids, isoflavonoids, hydroxycinnamic acids, free and bound sugars, pectin substances, polysaccharides, amino acids, $\beta$-sitosterol, umbelliferone, chlorophylls. Rutin contained in the sophora buds has a P-vitamin activity, reduces the fragility and permeability of the capillaries, together with ascorbic acid takes part in the oxidation-reduction processes, slows down the action of hyaluronidase, and has antioxidant action $[15,16]$.

Phaseoli vulgaris valvae fructus contains amino acids (arginine, lysine, tryptophan, tyrosine, leucine, asparagine), flavonoids, hemicellulose (45-50\%), macro- and micronutrients (silicon, copper, cobalt, nickel) [17]. The raw material has a diuretic, hypoglycemic, vasodilator effect, improves the metabolism of the body $[18,19]$.

Polygoni avicularis herba contains tannins, flavonoids (avicularin, izorametin, quercetin, camperferol, quercetin-3-arabinozide, luteolin, myrcetin), coumarins (scopoletin, smartleferon), saponins, organic acids, polysaccharide complex. The raw material prevents the formation and promotes the removal of urinary concretions in renal stone disease, increases diuresis, removes excess urine from sodium and chlorine, also reduces arterial pressure, increases contractions of the uterus, shows anti-inflammatory and anti-toxic effects [20].

\section{Results}

We have developed a composition of the herbal colection: Harpagophyti radix, Sophorae alabastra, Phaseoli vulgaris valvae fructus, Polygoni avicularis herba with the following ratio of components 50:20: 20:10. The presented collection reveals analgesic and anti-inflammatory properties and can be used for prophylaxis, auxiliary therapy of a number of conditions in rheumatology, for example, osteoarthritis, rheumatoid arthritis, osteoporosis, as an analgesic and anti-inflammatory agent. We determined quality indicators of the designed collection, the results are shown in Table 1.

Table 1

Results of determining the quality indices of the initial MPRM ( $n=5)$

\begin{tabular}{cccc}
\hline MPRM & $\begin{array}{c}\text { Loss in mass } \\
\text { after drying, \% }\end{array}$ & Ash total, \% & $\begin{array}{c}\text { Content of extractives } \\
\text { (extractant-water P) }\end{array}$ \\
\hline $\begin{array}{c}\text { Harpagophyti radix } \\
\text { Sophorae buds }\end{array}$ & $8.69 \pm 0.21$ & $4.25 \pm 0.28$ & $38.80 \pm 0.31$ \\
$\begin{array}{c}\text { Phaseoli vulgaris valvae } \\
\text { fructus }\end{array}$ & $9.33 \pm 0.32$ & $6.55 \pm 0.27$ & $32.63 \pm 0.36$ \\
Polygoni avicularis herba & $10.56 \pm 0.31$ & $8.56 \pm 0.23$ & $21.24 \pm 0.29$ \\
& $8.02 \pm 0.25$ & $6.28 \pm 0.41$ & $19.59 \pm 0.23$
\end{tabular}

According to the results of determining the content of mass loss during drying, it was established that for the MPRM of the investigated collection the value of this indicator was within the range of $8.02 \pm 0.25 \%$ (Polygoni avicularis herba) - $10.56 \pm 0.31 \%$ (Phaseoli vulgaris valvae fructus). The "Common ash" index varied within the range of $4.25 \pm 0.28$ (Harpagophyti radix) $8.56 \pm 0.23$ (Phaseoli vulgaris valvae fructus). The largest content of extractive substances was found in the raw Sophorae buds $(32.63 \pm 0.36)$, the smallest - in the Polygoni avicularis herba $(19.59 \pm 0.23)$.

Experimental data on the calculated technological parameters of the investigated plant raw material are given in Table 2. 
Table 2

Results of determination of technological parameters of raw material and collection $(n=5)$

\begin{tabular}{cccccc}
\hline Indicator & $\begin{array}{c}\text { Harpagophyti } \\
\text { radix }\end{array}$ & Sophorae buds & $\begin{array}{c}\text { Phaseoli vulgaris } \\
\text { valvae fructus }\end{array}$ & $\begin{array}{c}\text { Polygoni } \\
\text { avicularis herba }\end{array}$ & Herbal collection \\
\hline Specific mass, $\mathrm{g} / \mathrm{cm}^{3}$ & $1.549 \pm 0.02$ & $1.380 \pm 0.02$ & $1.417 \pm 0.03$ & $1.432 \pm 0.04$ & $1.387 \pm 0.03$ \\
Volumetric mass, $\mathrm{g} / \mathrm{cm}^{3}$ & $0.968 \pm 0.04$ & $0.627 \pm 0.03$ & $0.549 \pm 0.02$ & $0.581 \pm 0.02$ & $0.653 \pm 0.03$ \\
Bulk density, g/cm & $0.161 \pm 0.03$ & $0.118 \pm 0.02$ & $0.182 \pm 0.01$ & $0.126 \pm 0.01$ & $0.171 \pm 0.01$ \\
Porosity & 0.418 & 0.519 & 0.653 & 0.646 & 0.511 \\
Cleavage & 0.825 & 0.758 & 0.667 & 0.716 & 0.738
\end{tabular}

The difference in the rates of specific mass for different types of raw materials (from $1.380 \pm 0.02$ to $1.549 \pm 0.02$ ) indicated the possibility of stratification of raw materials during the production of the collection.

Taking into account the obtained data, the next step was to conduct studies to determine the optimal degree of MPRM grinding, which is included in the collection, which will allow obtain a homogeneous mixture and contribute to the maximum yield of extractive and active substances. The obtained data are presented in the Table 3.

\section{Table 3}

Influence of the degree of grinding of raw materials of designed collection samples on the yield of extractives and flavonoids (extractant-water)

\begin{tabular}{ccc}
\hline Indicator & Sample No. 1 (0.35-5.0 mm & Sample No. 2 (0.35-2.0 mm) \\
\hline Content of extractive substances, \% & $44.80 \pm 0.23$ & $58.41 \pm 0.21$ \\
Content of the flavonoids amount, $\%$ & $0.42 \pm 0.04$ & $0.51 \pm 0.02$
\end{tabular}

Data from experimental studies (Table 3) indicate that sample No. 2, the degree of raw material shredding from $0.35 \mathrm{~mm}$ to $2.0 \mathrm{~mm}$, had a significantly higher percentage yield of extractives and a quantitative content of flavonoids compared to sample No. 1, where the degree of grinding the raw material was from $0.35 \mathrm{~mm}$ to $5.0 \mathrm{~mm}$.

Based on the experimental data, a technological scheme for the production of herbal collection was developed based on the presented composition (Fig. 1).

Stage 1. Preparation of raw materials. Each type of raw material that is part of the collection was individually crushed with a $2 \mathrm{~mm}$ grass cutting machine and then washed with SLM-200 laboratory sieves $(0.35 \mathrm{~mm}$ and $2.0 \mathrm{~mm}$ holes $)$. The degree of shredding of raw materials ensures the uniformity of mixing the components of the developed collection and the maximum yield of active substances in a water extraction.

Control the particle size and homogeneity of the drying of the raw material.

Stage 2. Getting a collection. The mixing of crushed and sifted raw materials was carried out, starting with the lower components of plant components, gradually adding raw materials, which are registered in greater quantities.

Control the mass of raw materials and homogeneity of mixing.

Stage 3. Packing and marking. The resulting collection is packed in polyethylene bags. Together with the instructions, they are packed in cardboard packs of $100 \mathrm{~g}$.

Control the bag pack, completeness, correctness of the print (serial number, expiration date)

Stage 4. Packing the packages in the box. 40 packs are placed in a corrugated box, on which paste the group label with the number of stacker-packer.

Controlling the compliance of the graphic design of the series, the number of packs in the box, the complete set of boxes. 


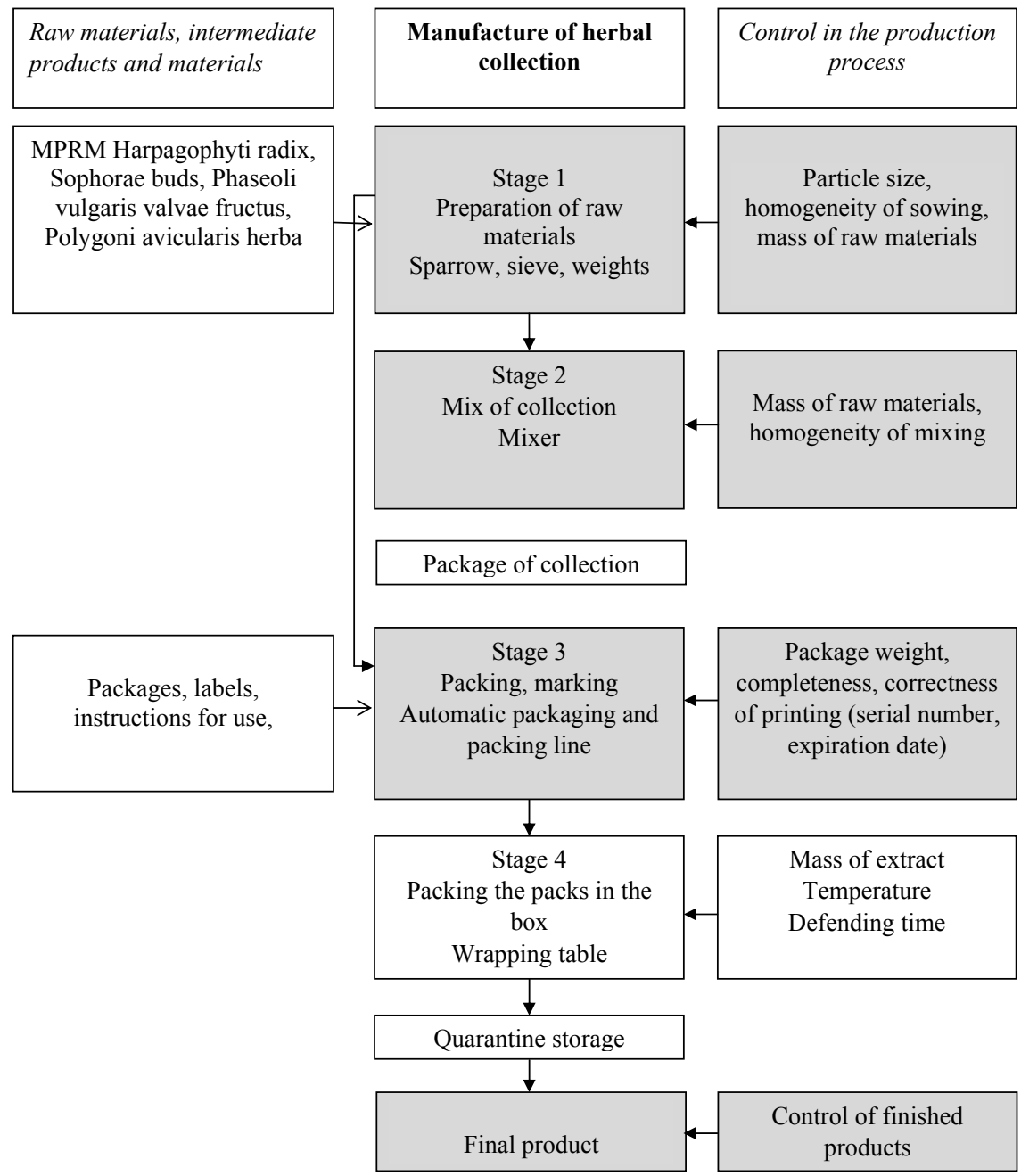

Fig. 1. Scheme of vegetable production

Taking into account that the medicinal plant collections are semi-finished products, the final product of which are water lifts prepared by patients at home, our further research was aimed at studying the effect of the method of infusion. For this purpose, infusion sets were prepared in the following modes: filling with boiling water and infusing for 15, 30, 45 and 60 minutes, as well as until fully cooled. The results of the conducted research are given in Table 4.

Table 4

Influence of the regime of infusion on the quality of water extracts from the collection $(n=5)$

\begin{tabular}{|c|c|c|c|}
\hline Regime of infusion & Organoleptic indexes & Extractive substances, \% & The content of flavonoids, $\%$ \\
\hline For $15 \mathrm{~min}$ & $\begin{array}{l}\text { Transparent with a specific aromatic odor, } \\
\text { light brown color }\end{array}$ & $40.15 \pm 0.39$ & $0.46 \pm 0.02$ \\
\hline For $30 \mathrm{~min}$ & $\begin{array}{l}\text { Transparent with a specific aromatic odor, } \\
\text { light brown color }\end{array}$ & $40.46 \pm 0.55$ & $0.48 \pm 0.01$ \\
\hline For $45 \mathrm{~min}$ & $\begin{array}{l}\text { Transparent with a specific aromatic odor, } \\
\text { light brown color }\end{array}$ & $47.76 \pm 0.41$ & $0.50 \pm 0.01$ \\
\hline For $60 \mathrm{~min}$ & $\begin{array}{l}\text { Transparent with a specific aromatic odor, } \\
\text { light brown color }\end{array}$ & $49.57 \pm 0.52$ & $0.52 \pm 0.03$ \\
\hline $\begin{array}{l}\text { Until } \\
\text { fully cooled }\end{array}$ & $\begin{array}{l}\text { Transparent with a specific aromatic odor, } \\
\text { light brown color }\end{array}$ & $51.90 \pm 0.39$ & $0.52 \pm 0.03$ \\
\hline
\end{tabular}


As can be seen from the data in Table 4, the content of extractives and flavonoids in the aqueous extraction gradually increases with time of infusion and reaches a maximum in 60 minutes. Because this method of infusion promotes the maximum removal of active substances, it can be recommended as the optimal for use at home in the application of collection.

\section{Discussion}

Based on literature data and our own experimental studies on the chemical composition and pharmacological activity of certain types of medicinal plant material, we have developed a plant collection that is recommended for the treatment and prevention of rheumatic diseases of the joints. Into the composition of the investigated collection were included (100 g): Harpagophyti radicis $50 \mathrm{~g}$, Sophora flower-bud $20 \mathrm{~g}$, Phaseoli vulgaris guava fructus $20 \mathrm{~g}$, Polygoni avicularis herba $10 \mathrm{~g}$.

Studies have been conducted on the development of quality collection indicators, which guarantee the effectiveness, safety, reproducibility of the imposed collection. The obtained values (Table 1) of the quality indices of the investigated raw materials correspond to the requirements of the corresponding monographs of the SPHU on these types of MPRM according to the indicators: "Loss in mass during drying", "General ashes", "Extractive substances".

During development of stages of preparation of plant raw materials, we have identified its main technological parameters: specific, bulk and volume mass, porosity, severity, degree of shredding. The rate of its wetting and swelling, absorbing ability depends on the porosity and singularity of the raw material. The higher the porosity, the more formed the internal juice when raw materials swelling. Cutting of the layer characterizes the size of the cavities between the pieces of crushed plant material. These technological parameters make it possible to determine the volume of dry and swollen raw materials, the necessary ratios of raw materials and extractants, and to select the necessary equipment for the processes of grinding, extraction, etc.

The obtained data concerning the technological parameters of raw materials indicate that the proposed collection consists of plants, the parts of which have different shape, size, mass and specific density, which may cause the layering of the components of the collection. To prevent uneven mixing, the optimal degree of grinding of the raw material of the designed collection is investigated, which would allow to obtain a homogeneous mixture and contribute to the maximum yield of extractive and active substances. It has been established that a significantly higher content of extractives and flavonoids was determined in the collection, where the degree of raw material grinding was from $0.20 \mathrm{~mm}$ to $0.35 \mathrm{~mm}$.

The technological parameters of the raw material obtained as a result of the research are necessary in the development of the technological scheme of production and determination of the extraction parameters. This is also confirmed by the results of scientific works devoted to the creation of medicinal products in the form of herbal collection [21, 22].

A number of experimental works aimed at studying the influence of the method of infusion (for 15, 30, 45, 60 minutes and until complete cooling) on the quality of the collected water extracts from the collection were also conducted. The optimal method for infusion of the collection is period for 60 minutes, since the content of extractives and flavonoids in the aqueous extract was highest and amounted to $49.57 \pm 0.52 \%$ and $0.52 \pm 0.03 \%$ respectively.

\section{Conclusions}

1. The composition of the herbal collection: Harpagophyti radicis, Sophora flower-bud, Phaseoli vulgaris valvae fructus, Polygoni avicularis herba with the following ratio of components: 50:20:20:10, respectively.

2. The technological parameters of raw materials were studied: specific, volumetric and bulk mass, porosity, singularity of raw materials. It was established that the optimal degree of grinding of raw materials in the assembly ranged from $0.20 \mathrm{~mm}$ to $0.35 \mathrm{~mm}$.

3. The composition and technological scheme of production of the designed collection and the established points of control in the process of production have been developed. 
4. The quality indicators of the collected collection were investigated: mass loss during drying $(9.46 \pm 0.29 \%)$, total ash $(4.53 \pm 0.32 \%)$, and extractives which were extracted with water $(55.24 \pm 0.02 \%)$.

5. It has been established that the recommended method of instilling a collection for patients is 60 minutes, since the content of extractives and flavonoids in the received water extract was the largest and was $49.57 \pm 0.52 \%$ and $0.52 \pm 0.03 \%$ respectively.

\section{References}

[1] Ash, Z., Gaujoux-Viala, C., Gossec, L., Hensor, E. M., FitzGerald, O., Winthrop, K. et. al. (2011). A systematic literature review of drug therapies for the treatment of psoriatic arthritis: current evidence and meta-analysis informing the EULAR recommendations for the management of psoriatic arthritis. Annals of the Rheumatic Diseases, 71 (3), 319-326. doi: http://doi.org/10.1136/ard.2011.150995

[2] Cameron, M., Chrubasik, S. (2014). Oral herbal therapies for treating osteoarthritis. Cochrane Database of Systematic Reviews. doi: http://doi.org/10.1002/14651858.cd002947.pub2

[3] Fernandes, L., Hagen, K. B., Bijlsma, J. W. J., Andreassen, O., Christensen, P., Conaghan, P. G. et. al. (2013). EULAR recommendations for the non-pharmacological core management of hip and knee osteoarthritis. Annals of the Rheumatic Diseases, 72 (7), 1125-1135. doi: http://oi.org/10.1136/annrheumdis-2012-202745

[4] Baloglu, H., Askin, A. (2015). Determination of the factors that affect healthrelated quality of life in patients with rheumatoid arthritis. Acta Medica Mediterranea, 31, 687-695.

[5] Patil, P. S., Rajani, S. (2010). An advancement of analytical techniques in herbal research. International Journal of Advanced Science and Research, 1 (1), 8-14.

[6] Sasidharan, S., Chen, Y., Saravanan, D., Sundram, K., Latha, L. (2010). Extraction, Isolation And Characterization Of Bioactive Compounds From Plants' Extracts. African Journal of Traditional, Complementary and Alternative Medicines, 8 (1). doi: http://doi.org/10.4314/ajtcam.v8i1.60483

[7] Santos, D. T., Veggi, P. C., Meireles, M. A. A. (2012). Optimization and economic evaluation of pressurized liquid extraction of phenolic compounds from jabuticaba skins. Journal of Food Engineering, 108 (3), 444-452. doi: http://doi.org/10.1016/j.jfoodeng.2011.08.022

[8] Anokwuru, C. P., Anyasor, G. N., Ajibaye, O., Fakoya, O., Okebugwu, P. (2011). Effect of extraction solvents on phenolic, flavonoid and antioxidant activities of three nigerian medicinal plants. Natural Science, 9, 53-61.

[9] Altemimi, A., Watson, D. G., Kinsel, M., Lightfoot, D. A. (2015). Simultaneous extraction, optimization, and analysis of flavonoids and polyphenols from peach and pumpkin extracts using a TLC-densitometric method. Chemistry Central Journal, 9 (1). doi: http://doi.org/10.1186/s13065-015-0113-4

[10] Mediani, A., Abas, F., Khatib, A., Tan, C. (2013). Cosmos Caudatus as a Potential Source of Polyphenolic Compounds: Optimisation of Oven Drying Conditions and Characterisation of Its Functional Properties. Molecules, 18 (9), 10452-10464. doi: http://doi.org/10.3390/molecules180910452

[11] Derzhavna Farmakopeia Ukrainy. Vol. 1 (2015). Kharkiv: Derzhavne pidpryiemstvo «Ukrainskyi naukovyi farmakopeinyi tsentr yak osti likarskykh zasobiv», 1128.

[12] Derzhavna Farmakopeia Ukrainy. Vol. 3 (2014). Kharkiv: Derzhavne pidpryiemstvo «Ukrainskyi naukovyi farmakopeinyi tsentr yak osti likarskykh zasobiv», 732.

[13] Inaba, K., Murata, K., Naruto, S., Matsuda, H. (2010). Inhibitory effects of devil's claw (secondary root of Harpagophytum procumbens) extract and harpagoside on cytokine production in mouse macrophages. Journal of Natural Medicines, 64 (2), 219-222. doi: http://doi.org/10.1007/s11418-010-0395-8

[14] Fiebich, B. L., Munoz, E., Rose, T., Weiss, G., McGregor, G. P. (2012). Molecular targets of the antiinflammatory Harpagophytum procumbens (devil's claw): inhibition of TNF $\alpha$ and COX-2 gene expression by preventing activation of AP-1. Phytotherapy Research, 26 (6), 806-811. doi: http://doi.org/10.1002/ptr.3636

[15] Xie, Z., Lam, S., Wu, J., Yang, D., Xu, X. (2014). Chemical fingerprint and simultaneous determination of flavonoids in Flos Sophorae Immaturus by HPLC-DAD and HPLC-DAD-ESI-MS/MS combined with chemometrics analysis. Anal. Methods, 6 (12), 4328-4335. doi: http://doi.org/10.1039/c4ay00289j

[16] He, X., Bai, Y., Zhao, Z., Wang, X., Fang, J., Huang, L. et. al. (2016). Local and traditional uses, phytochemistry, and pharmacology of Sophora japonica L.: A review. Journal of Ethnopharmacology, 187, 160-182. doi: http://doi.org/10.1016/j.jep.2016.04.014 
[17] Onyilagha, J. C., Islam, S. (2009). Flavonoids and other polyphenols of the cultivated species of the genus Phaseolus. International Journal of Agriculture and Biology, 11, 231-234.

[18] Helmstädter, A. (2010). Beans and Diabetes: Phaseolus vulgaris Preparations as Antihyperglycemic Agents. Journal of Medicinal Food, 13 (2), 251-254. doi: http://doi.org/10.1089/jmf.2009.0002

[19] Carai, M. (2009). Potential efficacy of preparations derived from Phaseolus vulgaris in the control of appetite, energy intake, and carbohydrate metabolism. Diabetes, Metabolic Syndrome and Obesity: Targets and Therapy, 2, 145-153. doi: http://doi.org/10.2147/dmso.s4236

[20] Jiao, L., Yan, C., Zhang, K., Xie, J., Zhang, Y., Wen, Z. (2018). Comprehensive determination of nine polyphenols in Polygoni Avicularis Herba with a new HPLC-DAD method and their correlation with the antioxidant activities. Journal of Food Measurement and Characterization, 12 (3), 1593-1600. doi: http:// doi.org/10.1007/s11694-018-9774-8

[21] Piminov, A. F. Beztsennaya, T. S., Shul'ga, L. I. (2014). Izuchenie vliyaniya farmatsevticheskikh faktorov na poluchenie vodnogo izvlecheniya iz lekarstvennogo rastitel'nogo sbora. Vestnik farmatsii, 1 (63), 27-32.

[22] Piskovatskyi, Yu. H., Vyshnevska, L. I., Heornhiiants, V. A. (2008). Rozrobka tekhnolohii likarskoho zboru «Bronkhofit». Medychna khimiia, 10 (1), 63-66. 